\title{
Neural Markers of Positive Reappraisal and Their Associations With Trait Reappraisal and Worry
}

\author{
Jason S. Moser, Rachel Hartwig, Tim P. Moran, \\ and Alexander A. Jendrusina \\ Michigan State University
}

\author{
Ethan Kross \\ University of Michigan
}

\begin{abstract}
Positively reinterpreting negative experiences is important for psychological well-being and represents a key mechanism of cognitive-behavioral therapies for emotional problems. Yet, little is known about the neural mechanisms that underlie this process and how they relate to clinically relevant individual differences. Here we demonstrate using event-related potentials (ERPs) that positively reappraising distress-inducing images is associated with early increases in frontal control activity and later decreases in parietal arousal-related activity. Moreover, we show that people's chronic tendencies to reappraise versus worry modulate neural activity in opposing directions-trait reappraisal predicts decreases in parietal arousal-related activity during positive reappraisal implementation whereas worry predicts increases in the same waveform. These findings provide novel insights into the neural time course of positive reappraisal. They also speak to the potential clinical utility of neurophysiological measures as relatively inexpensive, noninvasive biomarkers that could serve as risk indicators and treatment mediators.
\end{abstract}

Keywords: cognitive change, emotion regulation, event-related potentials, late positive potential, reappraisal, worry

The idea that people can reappraise their emotional experiences in ways that reduce their negative impact is a fundamental principle of Cognitive Behavioral Therapies (CBT; Beck, Emery, \& Greenberg, 1985; Clark \& Beck, 2010). Likewise, the capacity to do so naturally is linked to optimism and well-being (Scheier, Weintraub, \& Carver, 1986; Gross \& John, 2003; Nes \& Segerstrom, 2006). Over the past decade, an overwhelming amount of research has begun to explore the neural correlates of this process (for reviews, see Denny, Silvers, \& Ochsner, 2009; Ochsner \& Gross, 2005). Much of this work, however, has focused on a particular type of reappraisal called detached reappraisal (Gross, 1998; Shiota \& Levenson, 2009), which involves adopting the perspective of an emotionally detached, clinical observer to blunt emotional responses. Comparatively less is known about the neural mechanisms underlying positive reappraisal (Ochsner et al., 2004), which involves positively reinterpreting negative events (Jamieson, Nock, \& Mendez, 2012; Shiota \& Levenson, 2009). Given that CBT involves fostering adaptive, and often times more positive appraisals (Clark \& Beck, 2010; Beck, Rush, Shaw, \& Emery, 1979; Clark, 2001; Resick \& Schnicke, 1992), and that such reappraisal is a core aspect of well-being (Scheier et al., 1986; Nes \& Segerstrom, 2006), a better understanding of positive reappraisal is particularly important from a mental health standpoint.

Jason S. Moser, Rachel Hartwig, Tim P. Moran, and Alexander A. Jendrusina, Department of Psychology, Michigan State University; Ethan Kross, Department of Psychology, University of Michigan.

Correspondence concerning this article should be addressed to Jason S. Moser, Department of Psychology, Michigan State University, Psychology Building, 110-B, East Lansing, MI 48823. E-mail: jmoser@msu.edu
In fact, a recent study found that it was the effects of CBT on increasing positive self-appraisals that mediated outcome more so than its effects on decreasing negative self-appraisals (Goldin et al., 2013). We addressed this issue by examining a) the neurophysiological correlates of positive reappraisal using event-related potentials (ERPs), and b) whether and how two clinically relevant dimensions - trait reappraisal and worry-relate to its neurophysiological underpinnings.

\section{Neurophysiological Markers of Reappraisal}

We examined the neurophysiological markers of positive reappraisal using ERPs - brain signals that reflect the time course of neural mechanisms that underlie the way people process information. We used ERPs for two reasons. First, timing is paramount in emotion regulation theory and research (Dan-Glauser \& Gross, 2011; Gross, 1998; Sheppes \& Gross, 2011). Reappraisal is theorized to be an antecedent-focused emotion regulation strategy, which means it should affect the way people process information before an emotion is activated. ERPs have a millisecond temporal resolution. Thus, they allow for the examination of the precise time course of reappraisal in ways that other neural measures do not. Second, ERPs are relatively inexpensive and noninvasive. Thus, they can be readily used in applied settings.

We focused on two ERP waveforms that have been reliably linked with reappraisal: the stimulus preceding negativity (SPN) and the late positive potential (LPP). The SPN is part of a class of slow cortical potentials (SCPs) elicited in anticipation of a variety of cognitive and emotional task-relevant stimuli (Brunia, van Boxtel, \& Böcker, 2012; van Boxtel \& Bocker, 2004). For example, SCPs are generated when a cue signals the subsequent onset of a 
stimulus to be responded to, and when individuals await the presentation of an emotional stimulus or feedback regarding the correctness of a response. Studies suggest that early enhancement of the SPN reflects orienting to the cue whereas later increases reflect anticipation of and preparation to act on the upcoming stimulus. Two studies to date demonstrated enhanced early and late time windows of the SPN at frontal recording sites during reappraisal, suggesting increased anticipation of and preparation for implementing reappraisal (Moser, Krompinger, Dietz, \& Simons, 2009; Thiruchselvam, Blechert, Sheppes, Rydstrom, \& Gross, 2011). In both of these studies, however, participants were given the option to use both detached and positive reappraisal. Thus, it is unclear whether enhanced frontal SPN is associated with positive reappraisal per se.

The LPP is a broad positive deflection that reaches maximum amplitude 300-800 ms after the onset of motivationally relevant stimuli. It can last several seconds. A decade of research demonstrates that the LPP reflects the arousal properties of emotional stimuli. Indeed, the magnitude of the LPP is closely coupled with subjective ratings of arousal reactions to emotional pictures, further linking the LPP to emotional experience (e.g., Cuthbert, Schupp, Bradley, Birbaumer, \& Lang, 2000). Early time windows (300-1000 ms) index attention allocation whereas later time windows $(>1000 \mathrm{~ms})$ index memory and meaning-making stages. Support for this distinction comes from studies of the LPP indicating that earlier time windows are generally sensitive to nonemotional, attentional manipulations (Olofsson, Nordin, Sequeira, \& Polich, 2008) whereas later time windows predict better memory for picture content (Koenig \& Mecklinger, 2008; see also Olofsson et al., 2008 for a review). Moreover, descriptive phrases indicating how to interpret the meaning of upcoming emotional and nonemotional stimuli selectively modulate the later time window (Foti \& Hajcak, 2008; MacNamara, Foti, \& Hajcak, 2009). Both time windows, however, are enhanced in response to arousing stimuli regardless of their valence (Olofsson et al., 2008) and show strong associations with visual cortex and amygdala activity measured by functional MRI (fMRI; Liu, Huang, McGinnis-Deweese, Keil, \& Ding, 2012; Sabatinelli, Bradley, Fitzsimmons, \& Lang, 2005; Sabatinelli, Lang, Keil, \& Bradley, 2007), supporting their significance in emotional processing.

Importantly, the LPP is also sensitive to top-down attentional control (Schienle, Köchel, \& Leutgeb, 2011; Scharmüller, Leutgeb, Schäfer, Köchel, \& Schienle, 2011). Specifically, early and late time windows of the LPP are reliably reduced at centroparietal sites during reappraisal indicating reductions in arousalrelated attention and memory processes (Hajcak \& Nieuwenhuis, 2006; Moser, Hajcak, Bukay, \& Simons, 2006; Moser et al., 2009; Moser, Most, \& Simons, 2010; Thiruchselvam et al., 2011). Moreover, LPP decreases during reappraisal are associated with decreases in emotional experience (Hajcak \& Nieuwenhuis, 2006). There is preliminary evidence indicating that the LPP is also enhanced at frontal sites during reappraisal, which seems to reflect enhanced attentional control (Bernat, Cadwallader, Seo, Vizueta, \& Patrick, 2011). Again, however, extant research has not examined positive reappraisal specifically.

Given the lack of knowledge regarding the temporal unfolding of positive reappraisal, we focused specifically on this strategy (and this strategy alone) in the current investigation. We reasoned that positive reappraisal would take time to evolve, as individuals have to wait for an experience to occur or a stimulus to appear to have material to positively reinterpret. Thus, we hypothesized that the time course for positive reappraisal would be relatively slow, reflected in later ERPs associated with memory and meaning making.

\section{From the Lab to Everyday Life: Trait Reappraisal and Worry}

A central goal of cognitive interventions is to teach people skills in therapy that they learn to use habitually in their daily lives. Therefore, from a clinical standpoint an equally important question surrounding positive reappraisal concerns whether and how people who habitually activate this process do so differently from those who do not. We addressed this issue by focusing on two clinically relevant individual differences: trait reappraisal and worry. We focused on these two transdiagnostic dimensions (Aldao, NolenHoeksema, \& Schweizer, 2010; Barlow, 2002; Harvey, Watkins, Mansell, \& Shafran, 2004) to examine whether habitually reappraising emotional experiences adaptively (i.e., high trait reappraisers) or maladaptively (i.e., high trait worriers) in daily life would have implications for how people implement positive reappraisal in the lab.

We adopted a dimensional approach to explore these questions because contemporary models of anxiety-related pathology (Brown \& Barlow, 2009; Watson, 2005), and psychopathology more broadly (e.g., Krueger, 1999), indicate that mental health functioning represents a dimension along a continuum from mild to extreme, with disordered patients falling at the high end of extreme. This design choice also aligns well with recent efforts to develop novel ways for classifying psychopathology in neurobehavioral terms (Morris \& Cuthbert, 2012; Sanislow et al., 2010).

Trait reappraisal is an individual difference that reflects people's tendency to reinterpret their experiences to decrease negative or increase positive emotions. High scores on this dimension are consistently linked with psychological health (e.g., Gross \& John, 2003). Trait reappraisal is not an indicator of trait positive reappraisal per se, however. Rather, it is an individual difference that assesses people's general capacity to reinterpret emotionally arousing experiences in ways that improve the way one feels (i.e., reducing negativity or increasing positivity). We focused on this individual difference in the current work because this trait has strong links to psychological well-being, which make it an excellent candidate for better understanding individual differences in the implementation of an adaptive cognitive emotion regulation process like positive reappraisal.

In contrast, worry, or anxious apprehension, is a future-oriented cognitive process characterized by the expectation of and preparation for the worst (Barlow, 2002; Clark \& Watson, 1991; Nitschke, Heller, Imig, McDonald, \& Miller, 2001; York, Borkovec, Vasey, \& Stern, 1987). Worry is considered to be a dimensional construct cutting across normal and clinical populations, such that it can be adaptive at low levels and associated with anxiety disorders when it spirals out of control and becomes chronic (Borkovec, 1985; Borkovec, Robinson, Pruzinsky, \& DePree, 1983; Brown \& Barlow, 2009; Ruscio, Borkovec, \& Ruscio, 2001). Indeed, the cardinal symptom of Generalized Anxiety Disorder (GAD) is worry (Andrews et al., 2010). Given its transdiagnostic nature and its defining link to GAD_-perhaps the 
most "basic" anxiety disorder-understanding the underlying mechanisms of worry has the potential to inform theory and research of all anxiety disorders (Barlow, 2002).

Worry has been conceptualized not only as the cognitive component of anxiety but also as a maladaptive emotion regulation strategy in that it is concerned with generating ways in which one might deal with or prevent negative future events and experiences (Borkovec, 1994; Borkovec, Alcaine, \& Behar, 2004; Mennin, Heimberg, Turk, \& Fresco, 2005; Newman \& Llera, 2011). Unfortunately, solutions are rarely reached in chronic worries using this so-called "what-if" process of unproductive repetitive thought, but it continues nonetheless (Watkins, 2008). By negatively reappraising experiences in ways that catastrophize outcomes (Newman \& Llera, 2011), chronic worriers, and those diagnosed with $\mathrm{GAD}$, report engaging in reappraisal less often (Aldao \& Mennin, 2012; Zlomke \& Hahn, 2010).

Although worry and trait reappraisal are two separate constructs, we leveraged their inverse association here to demonstrate how individual differences in maladaptive and adaptive functioning, respectively, relate to the implementation of an adaptive emotion regulation strategy-positive reappraisal. In terms of predictions, we hypothesized that there were two ways that trait reappraisal and worry could influence the way people positively reappraise their experiences. One possibility is that trait reappraisers would be especially good at implementing positive reappraisal whereas worriers would perform less well. Gross and John (2003) referred to this as the practice effects model, which predicts that those who habitually use a particular strategy in daily life should demonstrate an advantage when asked to implement said strategy in the lab. Consistent with this expectation, McRae and colleagues (2012) recently found that trait reappraisal was associated with larger decreases in self-reported negative emotion when participants were asked to reappraise their emotions. However, as in the prior studies we reviewed, participants were given freedom to use different forms of reappraisal to feel better in this study and thus it is difficult to determine whether the results have relevance to positive reappraisal in particular. Moreover, this study did not speak to the neural underpinnings of individual differences in positive reappraisal implementation.

There are more data available to support this practice effects prediction in the context of worry. To date, studies indicate that anxious prone individuals (e.g., people who score high on trait anxiety measures, GAD patients, social phobic patients), who are characterized by the tendency to worry excessively engage in effortful processing when asked to implement reappraisal in the laboratory (Campbell-Sills et al., 2011; Goldin, Manber-Ball, Werner, Heimberg, \& Gross, 2009; Aldao \& Mennin, 2012). As with the trait reappraisal work, however, none of these studies focused specifically on positive reappraisal and none focused on the neural mechanisms underlying the relationship between trait worry and positive reappraisal implementation.

Alternatively, it is possible that there may be little variability in how individuals implement positive reappraisal in the lab, perhaps because positively reappraising negative experiences is an "overlearned behavior," as Gross and John (2003) proposed. That is, reappraisal might be used often enough by everyone that any practice advantage is minimal. Affective disorder research provides some support for the notion that individual differences in psychopathology may have little effect on positive reappraisal implementation in the lab. Behavioral evidence indicates, for example, that when anxious and depressed people are asked to implement strategies that involve different reappraisal operations, they can be successful (Campbell-Sills, Barlow, Brown, \& Hofmann, 2006; Ehring, Tuschen-Caffier, Schnülle, Fischer, \& Gross, 2010; also see, Kross \& Ayduk, 2009; Kross, Gard, Deldin, Clifton, \& Ayduk, 2012). Such patients also respond well to therapies whose primary technique is cognitive reappraisal (Clark \& Beck, 2010). As with the aforementioned research, however, none of these studies focused specifically on the neural mechanisms underlying positive reappraisal. Thus, whether they generalize to the current context is unclear.

\section{Research Overview}

In the current study, we examined neurophysiological markers of positive reappraisal and their associations with individual differences in trait reappraisal and worry. Because individuals in the current study were instructed to imagine positive outcomes to unpleasant scenes, we hypothesized that individuals would not be able to prepare their reappraisals ahead of time and thus the SPN would not be modulated. We further predicted reduced parietal LPP magnitude during positive reappraisal instructions in later memory and meaning making time windows. Regarding the frontal LPP, if generating alternative outcomes to unpleasant scenes cannot be achieved until the content appears, and this processes requires directed attentional control (Dunning \& Hajcak, 2009; Hajcak, Dunning, \& Foti, 2009; Schienle et al., 2011), we reasoned that the frontal LPP would be enhanced during picture processing in the reappraisal condition. Regarding trait reappraisal and worry, we considered two contrasting possibilities: a) consistent with the practice effects hypothesis, trait reappraisal would not be associated with SPN or frontal LPP, suggesting efficient use of preparatory and cognitive control processes, but would be associated with greater parietal LPP decreases during positive reappraisal implementation, and worry would be associated with enhanced SPN and frontal LPP as well as lesser decreases or paradoxical increases in parietal LPP during reappraisal implementation; or b) consistent with the overlearned behavior hypothesis, neither trait reappraisal nor worry would be associated with ERP modulations during positive reappraisal.

\section{Method}

\section{Participants}

Seventy-one females ${ }^{1}(M$ age $=22.28 ; S D$ age $=2.68)$ participated for course credit or $\$ 10$ per hour. We focused on females because a) previously reported sex differences in brain structure and function, including emotion processing and regulation, could obscure results (Canli, Desmond, Zhao, \& Gabrieli, 2002; Cahill et al., 2001; McRae, Ochsner, Mauss, Gabrieli, \& Gross, 2008) and b) women are twice as likely to suffer from anxiety-related problems (Kessler et al., 2005; Lewinsohn, Gotlib, Lewinsohn, Seeley, $\&$ Allen, 1998), thus making them a particularly clinically relevant

\footnotetext{
${ }^{1}$ A subset of the current sample was reported on elsewhere as part of a psychometric investigation of the LPP (Moran, Jendrusina, \& Moser, 2013).
} 
group to study. Native English speakers of all ethnic origins between the ages of 18 and 35 were considered. Our rationale for including individuals ranging in age from 18-35 was twofold: a) it minimizes age-related amplitude and scalp distribution differences in the ERPs of interest (e.g., Anderer, Semlitsch, \& Saletu, 1996; McEvoy, Pellouchoud, Smith, \& Gevins, 2001), and b) this age range represents a period of increased risk for worry-related pathology (American Psychiatric Association, 2013; Kessler, Petukhova, Sampson, Zaslavsky, \& Wittchen, 2012). The selfidentified ethnic breakdown of participants was as follows: $64.8 \%$ Caucasian/White, 9.9\% African American, 1.4\% Latino/Hispanic, $2.8 \%$ Asian, and $4.2 \%$ Biracial/Multiracial. The remaining $16.9 \%$ of the sample did not report their ethnicity.

To ensure an adequate spread of worry symptoms and increase the clinical relevance of the current findings, a subset of participants were preselected based on their Penn State Worry Questionnaire scores (PSWQ; Meyer, Miller, Metzger, \& Borkovec, 1990), which we obtained during a brief phone interview: 19 participants were chosen who scored at or above the clinical cutoff (PSWQ = 62) for GAD (Behar, Alcaine, Zuellig, \& Borkovec, 2003) and 18 participants were chosen who scored below a 40 on the PSWQ, which corresponds to the average score for nonanxious samples (e.g., Aldao \& Mennin, 2012). All other participants were chosen without regard to PSWQ scores.

\section{Stimuli and Procedures}

The stimulus set consisted of 60 color International Affective Picture System images (IAPS; Lang, Bradley, \& Cuthbert, 1999): 30 neutral, low-arousal images $\left(M_{\text {valence }}=4.92 ; M_{\text {arousal }}=2.85\right)$ and 30 negative, high-arousal images $\left(M_{\text {valence }}=2.30 ; M_{\text {arousal }}=\right.$ 6.37). ${ }^{2}$

For each trial, participants first viewed an instruction phrase ("REAPPRAISE NEGATIVE," "LOOK NEGATIVE," or "LOOK NEUTRAL") for $2 \mathrm{~s}$ that directed them how to respond to the following picture. The "REAPPRAISE NEGATIVE" phrase indicated that participant should imagine that the pictured scene improved and to think of the image in a more positive light so as to decrease the intensity of their negative emotions (see also Ochsner et al., 2004). The instruction phrases "LOOK NEGATIVE" and "LOOK NEUTRAL" indicated that the participant should respond naturally to the presented negative and neutral images, respectively. We did not include a "REAPPRAISE NEUTRAL" instruction phrase for two main reasons: a) to be consistent with the majority of prior reappraisal research in which a reappraise-neutral condition was omitted (e.g., Hajcak \& Nieuwenhuis, 2006; McRae et al., 2010; Paul, Simon, Kniesche, Kathmann, \& Endrass, 2013; Thiruchselvam et al., 2011), and b) our experience in prior work (Krompinger et al., 2008; Moser et al., 2006, 2009, 2010) has been that it is difficult to design reappraisal instructions for regulating responses to emotionally neutral stimuli (e.g., coffee cups, baskets, office scenes) that subjects can understand and easily and reliably implement. After the instruction phrase was presented, a blank screen occupied the screen for $500 \mathrm{~ms}$ followed by a centrally presented white fixation cross lasting $500 \mathrm{~ms}$. Following the fixation cross, the IAPS images were displayed on the full screen of a 19-inch monitor for $6 \mathrm{~s}$. A period of $2.5 \mathrm{~s}$ was inserted between the offset of images and the presentation of the next instruction phrase during which time participants were instructed to relax and clear their minds.

Participants first completed two practice blocks of the reappraisal task to familiarize themselves with the timing of events and instructions. The reappraisal task then included 90 cue-picture trials: 30 REAPPRAISE NEGATIVE, 30 LOOK NEGATIVE, and 30 LOOK NEUTRAL trials. The order of trials was random and the 30 negative IAPS images were used for both the REAPPRAISE NEGATIVE and LOOK NEGATIVE trials to control for stimulus properties (see Moser et al., 2009 for similar method). LOOK NEUTRAL trials were included as fillers to buffer against possible habituation to the negative images and thus are not considered in analyses described below (see Ochsner et al., 2004 for the same approach).

After the instructed reappraisal task, participants completed a questionnaire assessing their emotional reactions $(1=$ very weak, $7=$ very strong $)$ and effort expenditure $(1=$ very little, $7=$ very $m u c h$ ) for each trial type as a manipulation check. Participants also completed the Emotion Regulation Questionnaire (ERQ; Gross \& John, 2003) and the PSWQ (Meyer et al., 1990). The cognitive reappraisal subscale of the ERQ (ERQ-R) was the focus of the current investigation. Finally, participants completed the Beck Depression Inventory-II (BDI-II; Beck, Steer, Ball, \& Ranieri, 1996) and the State Trait Anxiety Inventory - Trait version (STAI-T; Spielberger \& Gorsuch, 1983) to more fully characterize the range of psychopathology affecting the current sample. We omitted the suicide item on the BDI-II in accordance with our Institutional Review Board's (IRB) standards for conducting research with nonclinical samples. ${ }^{3}$ Thus, the scores we report may represent a lower estimate of the true severity of the current sample. Some participants failed to complete all questionnaires, thus sample sizes vary slightly across analyses presented below.

We decided to administer the questionnaires after the emotion regulation task so as to a) protect the ERP task from any priming toward negative emotions if given first, and b) not burden subjects at the outset. Some evidence also suggests that when such questionnaires are given has little effect on emotion regulation manipulations (Kross \& Ayduk, 2009). Specifically, Kross and Ayduk examined whether administering individual difference measures similar to those used here before versus after a type of reappraisal manipulation influenced the effects of that manipulation and found that it did not. Given that these questionnaires tap more stable traits or symptoms (as they reference at least the past 1-2 weeks), we also reasoned that the brief emotion regulation task would have little effect on them.

As a result of our recruitment strategy, which aimed to clinically "enrich" our sample (Jaffee et al., 2005), approximately 39\% of

\footnotetext{
2 The ID numbers of the IAPS pictures used were the following: Neutral (2190, 2200, 2210, 2230, 2570, 2840, 5500, 5531, 7000, 7002, 7009, 7010, 7020, 7025, 7035, 7050, 7080, 7100, 7150, 7160, 7170, 7175, 7190, 7217, $7224,7233,7235,7550,7700,5950)$; Unpleasant $(2688,6312,6313,6825$, $9425,9428,9620,9622,9908,3181,3350,3500,3530,6212,6821,2683$ $2811,3301,6550,6520,8485,9050,9183,9414,6242,6231,6230,3170$, 3220, 9903).

${ }^{3}$ Our IRB stipulates that studies not including clinical screening/interviewing and trained staff to manage emergency situations should omit suicide screening. We complied with this policy despite the importance of screening for suicidality and identifying those who could benefit from intervention.
} 
participants scored above the clinical cutoff of 62 on the PSWQ, suggesting we were successful at obtaining a representative number of individuals likely suffering from clinically significant anxiety-related problems. The mean BDI-II score was 10.54 $(S D=7.97 ; n=62)$ and the mean STAI-T score was $40.69(S D=$ $12.05 ; n=62$ ). Adjusting for the missing suicide item on the BDI-II, $19 \%$ of the sample reported experiencing moderate to severe depressive symptoms based on the standard severity ranges (Beck et al., 1996). Even with the missing suicide item, the mean reported for the current sample is double that reported for control samples in other emotion regulation studies of anxiety (e.g., Goldin et al., 2009). The average STAI-T score falls between high and low trait anxious samples in other ERP studies of the LPP (e.g., Holmes, Nielsen, Tipper, \& Green, 2009), suggesting adequate spread of trait anxiety symptoms.

\section{Psychophysiological Recording and Data Reduction}

Continuous encephalographic (EEG) activity was recorded using the ActiveTwo Biosemi system (Biosemi, Amsterdam, The Netherlands). Recordings were taken from $64 \mathrm{Ag}-\mathrm{AgCl}$ electrodes embedded in a stretch-lycra cap. Additionally, two electrodes were placed on the left and right mastoids. Electro-oculogram (EOG) activity generated by eye-movements and blinks was recorded at FP1 and three additional electrodes placed inferior to the left pupil and on the left and right outer canthi. During data acquisition, the EEG signal was preamplified at the electrode to improve signalto-noise ratio and amplified with a gain of $1 \times$. The data were digitized at 24-bit resolution with a least significant bit value of $31.25 \mathrm{nV}$ and a sampling rate of $512 \mathrm{~Hz}$, using a low-pass fifth order sinc filter with a $-3 \mathrm{~dB}$ cutoff point at $104 \mathrm{~Hz}$. The Common Mode Sense (CMS) active electrode, located between $\mathrm{POz}$ and PO4, served as the online reference for all other electrodes. CMS forms a feedback loop with a paired Driven Right Leg passive electrode, located between $\mathrm{POz}$ and PO3, reducing the amount of current that can possibly return to the participant.

Offline analyses were performed using BrainVision Analyzer 2 (BrainProducts, Gilching, Germany). Scalp electrode recordings were rereferenced to the mean of the mastoids and band-pass filtered (cutoffs: $0.01-30 \mathrm{~Hz} ; 12 \mathrm{~dB} /$ oct rolloff). Ocular artifacts were corrected using the method developed by Gratton, Coles and Donchin (1983). Stimulus-locked data were segmented into individual epochs beginning $200 \mathrm{~ms}$ before cue and picture onset and continuing for 3 and 8s, respectively. Cue- and picture-locked epochs were computed separately for REAPPRAISE NEGATIVE and LOOK NEGATIVE trials. Physiologic artifacts were detected using a computer-based algorithm such that trials in which the following criteria were met were rejected: a voltage step exceeding $50 \mu \mathrm{V}$ between contiguous sampling points, a voltage difference of $300 \mu \mathrm{V}$ within a trial, and a maximum voltage difference of less than $0.5 \mu \mathrm{V}$ within 100 -ms intervals. When artifacts were detected, all channels from that trial were discarded. In some cases, visual inspection indicated that only one channel or a small group of localized channels contained artifacts. For these trials, only those channels with artifacts were removed and the remainder were retained. If the channels with artifacts were locations of interest (e.g., Pz) we utilized the spherical spline interpolation method to retain the electrodes for analysis.
An average waveform for each condition was generated for each participant. Grand average waveforms were then created by averaging all individual participant waveforms. Grand average waveforms are generated to visualize overall effects and determine component time windows for statistical analysis. Statistical analyses for each component defined below were conducted on averages from each participant.

The SPN was identified and quantified at fronto-central electrodes (F1, Fz, F2, FC1, FCz, FC2). First, a baseline equal to the average activity in the $-200-0 \mathrm{~ms}$ precue window was subtracted from each data point subsequent to stimulus onset. The early SPN was then defined as the average voltage in the 300-2000 ms time window postcue onset. The late SPN was defined as the average voltage in the 2300-3000 ms time window postcue onset, corresponding to the $700 \mathrm{~ms}$ immediately preceding picture onset during which time participants viewed the blank screen and fixation cross separating the cue and the picture.

The LPP was identified and quantified at two regions of interest: fronto-central (F1, Fz, F2, FC1, FCz, FC2) and parietal (CPz, P1, $\mathrm{Pz}, \mathrm{P} 2, \mathrm{POz})$. First, a baseline equal to the average activity in the $-200-0$ ms prepicture window was subtracted from each data point subsequent to stimulus onset. Based on visual inspection and previous reports the fronto-central LPP was then defined as the average voltage between $750 \mathrm{~ms}$ and $1050 \mathrm{~ms}$ post-picture onset. With regard to the parietal LPP, we followed conventions from previous research (Cuthbert et al., 2000). Specifically, we defined the parietal LPP as the average voltage in successive time windows: 400-700 ms, 700-1000 ms, 1-2 s, 2-3 s, 3-4 s, 4-5 s, and 5-6 s. Finally, to examine the persistence of ERP modulation by reappraisal instructions we also examined the parietal LPP following picture offset in the $6-7 \mathrm{~s}$ and $7-8 \mathrm{~s}$ post-picture onset time windows (corresponding to $0-1 \mathrm{~s}$ and $1-2 \mathrm{~s}$ post-picture offset; Hajcak \& Olvet, 2008).

\section{Results}

\section{Neural Signature of Positive Reappraisal}

Overview of analyses. We first report results examining the effects of positive reappraisal (i.e., task instruction effects). To do so we performed repeated measures analyses of variance (rANOVAs) on ERP measures with Greenhouse-Geisser correction applied to $p$ values associated with multiple $d f$ repeated measures comparisons where appropriate. Only effects involving differences between REAPPRAISE NEGATIVE and LOOK NEGATIVE trials are presented. Thus, all rANOVAs included the two-level factor Instruction Phrase (REAPPRAISE NEGATIVE vs. LOOK NEGATIVE). From here on, we refer to this contrast as "positive reappraisal related neural activity."

The early and late SPN were analyzed using two separate rANOVAs involving the two-level Instruction Phrase factor as described above. Because the parietal LPP is a broad and sustained waveform we conducted several different analyses of its amplitude across time, following convention (Cuthbert et al., 2000; Moser et al., 2009). The first two time windows $-400-700$ and 700-1000 ms-were analyzed together as reflecting maximal LPP processes in a 2 (Instruction Phrase: REAPPRAISE NEGATIVE vs. LOOK NEGATIVE) $\times 2$ (Time Window: 400-700 vs. 700-1000 ms) rANOVA. Then, the LPP was evaluated from 1-6 seconds in 1-s 
bins to index sustained LPP processes using a 2 (Instruction Phrase: REAPPRAISE NEGATIVE vs. LOOK NEGATIVE) $\times 5$ (Time Window: $1-2 \mathrm{~s}$ vs. $2-3 \mathrm{~s}$ vs. $3-4 \mathrm{~s}$ vs. $4-5 \mathrm{~s}$ vs. 5-6 s) rANOVA. Last, the two LPP time windows after picture offset were analyzed together in a 2 (Instruction Phrase: REAPPRAISE NEGATIVE vs. LOOK NEGATIVE) $\times 2$ (Time Window: $6-7 \mathrm{~s}$ vs. 7-8 s) rANOVA. Two outliers were identified in the parietal LPP analyses and thus were removed from all subsequent analyses. $^{4}$

SPN. We did not observe an effect of positive reappraisal on the early or late SPN, $F \mathrm{~s}(1,70)<1.60, p \mathrm{~s}>.22$, $\eta_{\mathrm{ps}}^{2}<.03$, $\varepsilon s=1$.

Fronto-central LPP. Confirming our prediction, positive reappraisal was associated with an enhanced fronto-central LPP, $F(1,70)=4.01, p<.05, \eta_{\mathrm{p}}^{2}=.05, \varepsilon=1$ (see Figure 1).

Parietal LPP. Analysis of the maximal LPP time windows400-700 ms and 700-1000 ms-revealed no effect of positive reappraisal, $F(1,68)<1, \varepsilon=1$. Analysis of the sustained LPP in the $1-6 \mathrm{~s}$ time window in $1-\mathrm{s}$ bins, however, confirmed our prediction that positive reappraisal would reduce LPPs in this later time window, $F(1,68)=8.83, p<.01, \eta_{\mathrm{p}}^{2}=.12, \varepsilon=1$. This effect did not change across time, $F(2.05,139.48)=2.13, p>.10$, $\eta_{\mathrm{p}}^{2}=.03, \varepsilon=.51$ (see Figure 1). Finally, there was no effect of positive reappraisal on the parietal LPP following picture offset, $F \mathrm{~s}<1, \varepsilon=1$.

Summary and discussion. Overall, the SPN and LPP findings suggest that positive reappraisal's effects occur primarily during picture, not cue, processing. Specifically, positive reappraisal seems to be associated with an increase in early attentional control and decreases in later arousal-related memory representations.

\section{Do Trait Reappraisal and Worry Modulate Positive Reappraisal Related Neural Activity?}

Overview of analyses. We examined how trait reappraisal and worry modulated positive reappraisal related neural activity by entering trait reappraisal and trait worry scores into separate rANOVAs as predictors. This allowed us to assess the separate main and interactive effects of trait reappraisal and worry on ERP measures. When significant effects of trait reappraisal and worry were detected, correlational analyses are presented to aid in interpretation of results. Correlations reflect the associations between questionnaire measures and the REAPPRAISE NEGATIVE minus LOOK NEGATIVE difference score. Degrees of freedom vary slightly across analyses due to missing questionnaire data. As expected, ERQ-R scores were negatively correlated with PSWQ scores $(r=-.36, p<.01)$, confirming greater self-reported use of reappraisal for those reporting lower worry symptoms and vice versa.

SPN. Trait reappraisal was unrelated to early and late SPN ( $p \mathrm{~s}>.70, \varepsilon s=1)$. In contrast, worry interacted with task instruction during the early and late SPN time windows, $F \mathrm{~s}(1,60)>$ $4.54, p \mathrm{~s}<.05, \eta_{\mathrm{ps}}^{2}=.07, \varepsilon \mathrm{s}=1$. Correlational analysis indicated that worry was associated with enhanced reappraisal-related early and late SPN amplitude $(r \mathrm{~s}=-.27, p \mathrm{~s}<.05$; the negative correlations indicate a positive association because the SPN is a negative-going ERP; see Figures 2 and 5).
Fronto-central LPP. Neither trait reappraisal nor worry produced any significant effects for fronto-central LPP ( $p$ s $>.35$, $\varepsilon \mathrm{s}=1)$.

Parietal LPP. During the maximal LPP time windows400-700 ms and 700-1000 ms-trait reappraisal produced no significant effects $(p \mathrm{~s}>.06, \varepsilon \mathrm{s}=1)$. Worry significantly interacted with task instructions, however, $F(1,58)=11.74, p=.001$, $\eta_{\mathrm{p}}^{2}=.17, \varepsilon=1$. Correlational analysis indicated that worry was associated with larger positive reappraisal related LPP increases $(r=.41, p=.001$; see Figures 4 and 5$)$. There were no other significant effects $(p s>.28)$.

The sustained positive reappraisal related LPP $-1-6$ secondswas related to trait reappraisal, $F(1,67)=14.60, p<.001, \eta_{\mathrm{p}}^{2}=$ $.18, \varepsilon=1$, and, moreover, this effect changed with time, $F(2.12$, $142.06)=5.47, p<.01, \eta_{\mathrm{p}}^{2}=.08 \varepsilon=.53$. Correlational analysis indicated that greater trait reappraisal was associated with significantly greater positive reappraisal related LPP decreases $(r=-.42, p<.001)$. The three-way interaction involving time indicated that this relationship grew from 1-6 seconds: $r=-.15$, $p=.23$ from $1-2 \mathrm{~s} ; r=-.29, p<.05$ from $2-3 \mathrm{~s} ; r=-.44, p<$ .001 from $3-4 \mathrm{~s} ; r=-.43, p<.001$ from $4-5 \mathrm{~s} ; r=-.47, p<$ .001 from $5-6 \mathrm{~s}$ (see Figures 3 and 5). No other effects involving trait reappraisal were significant $(p s>.15)$.

Worry was also associated with sustained positive reappraisalrelated LPP amplitude across the full 1-6 s time window, $F(1$, $58)=4.99, p<.05, \eta_{\mathrm{p}}^{2}=.08, \varepsilon=1$. Correlational analysis showed that higher worry scores were associated with significantly greater positive reappraisal related LPP increases $(r=.28, p<$ $.05)$. This association did not change across time, $F(2.03,117.88)$ $p<1, \varepsilon=.51$. When both trait reappraisal and worry were entered into a simultaneous entry regression predicting positive reappraisal related LPP amplitude across the full 1-6 s time window, trait reappraisal remained a significantly predictor $(\beta=-.43, p=$ $.001)$ whereas PSWQ did not $(\beta=.14, p>.25)$.

Finally, trait reappraisal was associated with positive reappraisal related LPP amplitude after picture offset $(F(1,67)=7.77, p<$ $\left..01, \eta_{\mathrm{p}}^{2}=.10, \varepsilon=1\right)$. Specifically, higher reappraisal was associated with decreased positive reappraisal related LPP amplitude from $6-8$ seconds post-picture offset $(\mathrm{r}=-.32, p<.01$; See Figures $3 \& 5$ ). No other effects involving trait reappraisal were significant $(p s>.13, \varepsilon s=1)$. Worry scores were unrelated to parietal LPP activity following picture offset ( $p s>.16$, $\varepsilon s=1$ ).

Summary and discussion. In sum, worry, but not reappraisal, potentiated the amplitude of the SPN associated with anticipatory and preparatory processes. Moreover, trait reappraisal and worry had opposing effects on the LPP such that trait reappraisal was associated with later LPP decreases, which prior research suggests indexes memory and meaning making whereas worry was associated with early LPP increases which have been linked with attention.

\section{Emotion and Effort Ratings}

Analysis of the self-reported emotional intensity ratings revealed a significant effect of task instructions, $F(1,67)=14.95$, $p<.001, \eta_{\mathrm{p}}^{2}=.18, \varepsilon=1$. As expected, participants reported

\footnotetext{
${ }^{4}$ The pattern of effects reported were the same, and when significant remained so at $p<.05$, when outliers were included in analyses.
} 
A

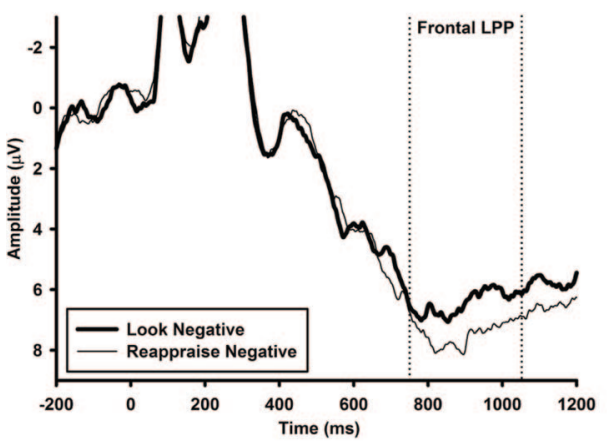

Frontal LPP

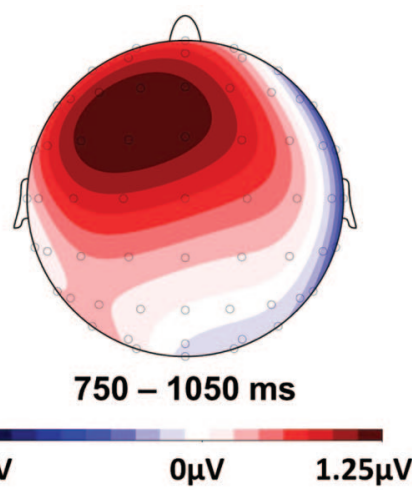

Parietal LPP

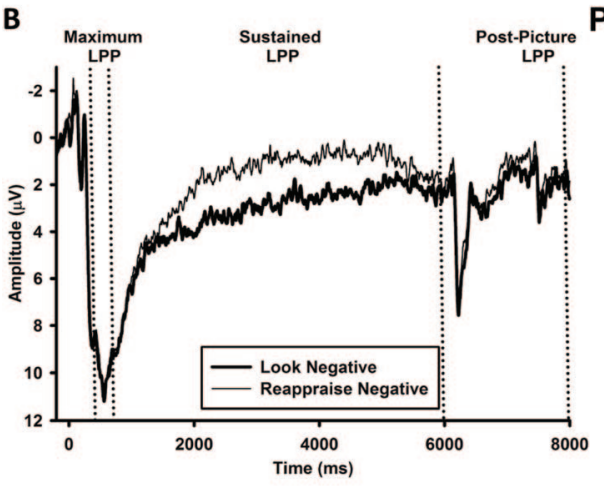

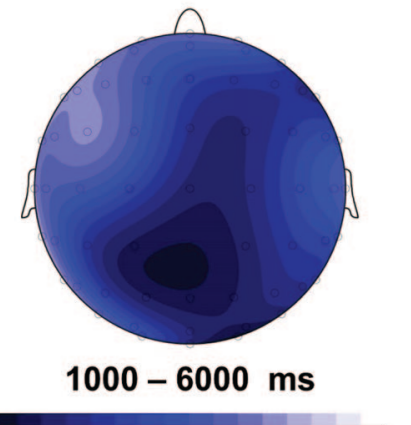

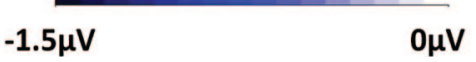

Figure 1. A, Picture-locked ERPs, pooled at fronto-central sites (F1, Fz, F2, FC1, FCz, FC2). LPP time window submitted to statistical analyses is identified with dotted lines. 0 represents picture onset. B, Picturelocked ERPs pooled at parietal sites (CPz, P1, Pz, P2, POz). Picture onset and offset indicated by dotted lines. LPP time windows submitted to statistical analyses are identified with dotted lines. 0 represents picture onset. In both panes, the headmaps show the topographical distribution of the Reappraise Negative minus Look Negative difference wave.

experiencing a weaker emotional reaction during positive reappraisal $(M=4.97)$ than during passive viewing $(M=5.50)$. Neither trait reappraisal nor worry scores were related to emotion ratings $(p s>.16, \varepsilon s=1)$.

Analysis of the self-reported effort ratings also revealed a significant effect of task instructions, $F(1,67)=64.00, p<.001$, $\eta_{\mathrm{p}}^{2}=.49, \varepsilon=1$, such that participants reported expending more effort during positive reappraisal $(M=5.24)$ than passive viewing $(M=3.15)$. Trait reappraisal was unrelated to effort ratings ( $p \mathrm{~s}>$ .17 , $\varepsilon s=1)$. However, worry scores were related to overall effort ratings (main effect of PSWQ, $F(1,60)=10.23, p<.01, \eta_{\mathrm{p}}^{2}=$ $.15, \varepsilon=1$; the interaction between PSWQ scores and task instructions was not significant, $F(1,60)=1.38, p=.25, \eta_{\mathrm{p}}^{2}=.02, \varepsilon=$ $1)$. Correlational analysis showed that higher worry scores were associated with greater self-reported effort expenditure during positive reappraisal and passive viewing $(r=.38, p<.01$; see Figure 5).

\section{Discussion}

This study addressed two questions: a) what is the neural time course of positive reappraisal, and b) how do individual differences in trait reappraisal and worry modulate this time course?

With respect to the first question, we found that positive reappraisal was not associated with the cue-locked frontal SPN that indexes preparatory activity. On the other hand, positive reappraisal led to an initial enlargement of the frontal LPP, suggesting enhancement of cognitive control, followed by decreases in the parietal LPP associated with emotion-related memory and meaning making processes.

With respect to the second question, we found that trait reappraisal facilitated parietal LPP decreases by positive reappraisal instructions during and after picture processing. In contrast, worriers showed enhanced frontal SPN, indexing enhanced preparation during cue processing, and paradoxical parietal LPP increases during positive reappraisal implementation.

\section{Basic Science Implications}

This is the first study to demonstrate the neural time course of positive reappraisal using ERPs. Confirming our prediction, the ERP findings suggest that emotional content must be present for individuals to generate positive outcomes and thus there is little preparation that can be done during the cue-to-picture period. Specifically, we found that positive reappraisal instructions did not modulate the amplitude of the SPN. In two prior studies, reappraisal instruction cues elicited enhanced SPNs (Moser et al., 2009; Thiruchselvam et al., 2011). This effect was interpreted as reflecting anticipation of and preparation for engaging in reappraisal processes. In our earlier study (Moser et al., 2009); how- 
A

High Trait Worry
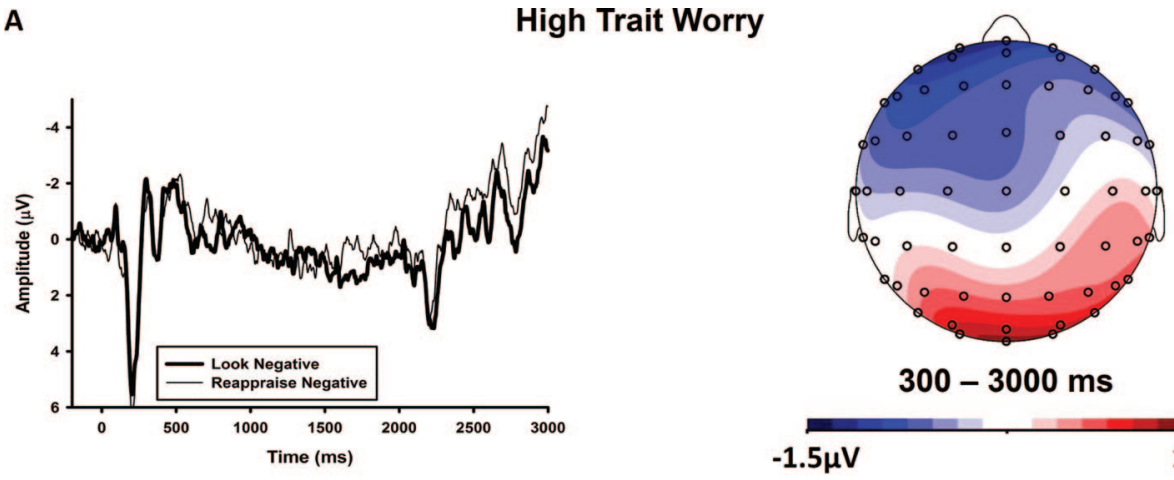

B

Low Trait Worry
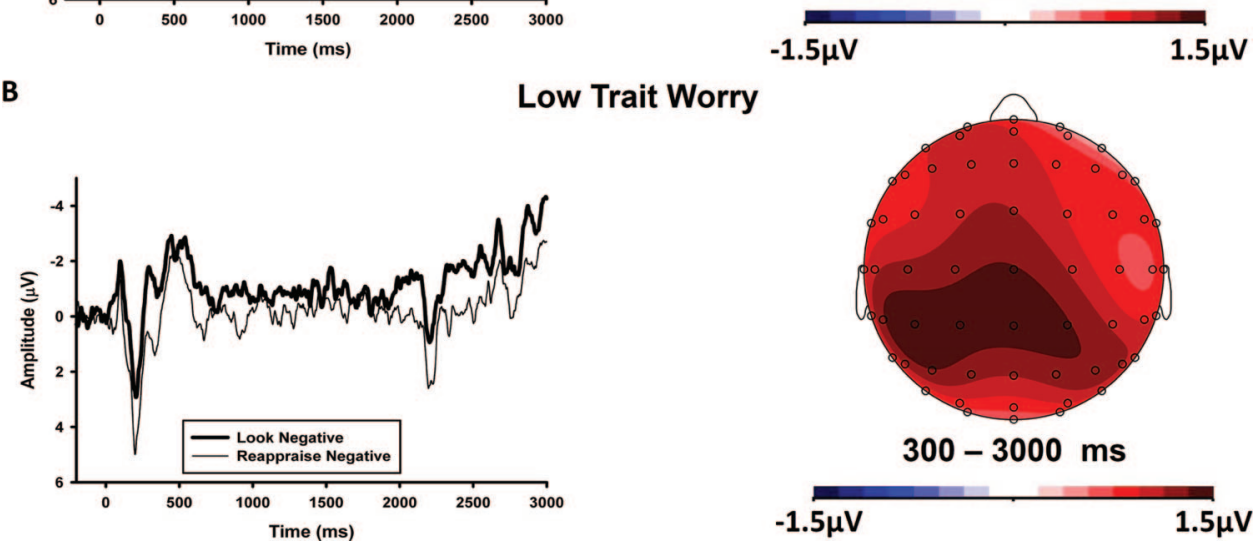

Figure 2. Cue-locked ERPs, pooled at fronto-central sites (F1, Fz, F2, FC1, FCz, FC2), shown separately for high (A) and low (B) trait worriers (defined by a median split procedure for graphical purposes only). Headmaps show the topographical distribution of the Reappraise Negative minus Look Negative difference wave for the two groups.

ever, we observed this enhancement of the SPN only to the reappraisal cue instructing participants to decrease emotional responses to negative pictures and not to the cue instructing participants to increase emotional responses. Because participants in that study utilized detached reappraisal to decrease responses, we reasoned that enhanced SPN to the decrease cue indexed the preparation of a neutral, distant mode of processing. Consonant with this reasoning, Thiruchselvam et al. (2011) also found enhanced SPN to a cue instructing participants to distract themselves using neutral imagery unrelated to the negative stimuli they were about to see. In contrast, SPN was not modulated when participants reported imagining themselves or a loved-one in the negative scenes they saw so as to personalize and increase their negative reactions in our previous study (Moser et al., 2009). Thus, we speculated that emotional content was necessary to generate such imagery to increase emotions. The current findings resonate with this interpretation insomuch as both positive reappraisal and increasing negative emotions by personalization require the presence of emotional content to generate alternative representations of the pictured scene for the purposes of modulating emotional reactions.

We also found that positive reappraisal was associated with decreases in the LPP during the sustained portion of the waveform, beginning around $1 \mathrm{~s}$ poststimulus onset, but not earlier when it reached its maximum amplitude between $400 \mathrm{~ms}$ and $1 \mathrm{~s}$. In the context of previous LPP research (Foti \& Hajcak, 2008; MacNamara, Foti, \& Hajcak, 2009; Olofsson et al., 2008), these findings suggest that positive reappraisal acts on elaborative memory and meaning-making processes rather than on earlier attention allocation mechanisms.

Taken together, these findings demonstrate that it is not the case that all reappraisal strategies are "antecedent," or occur before an emotional response is generated (Gross, 1998; Gross \& Thompson, 2007). More broadly, they suggest that "reappraisal" should not be treated as a homogenous strategy category. Rather they demonstrate that different types of reappraisals have different biopsychosocial consequences (for similar argument, see Shiota \& Levenson, 2009).

Our findings regarding trait reappraisal and worry provide the first ERP support for the practice effects hypothesis. Trait reappraisal facilitated parietal LPP reductions between 1 and 6 seconds post-picture onset, during which the overall sample demonstrated LPP reductions. Thus, trait reappraisal facilitated similar processing stages that are involved in instructed reappraisal. Moreover, trait reappraisal had stronger effects on parietal LPP decreases across time and continued to exert its effects following picture offset. Trait reappraisal therefore not only facilitated emotion regulation processes that result in less arousing representations of unpleasant stimuli, it sustained these regulatory effects for several seconds. The current neurophysiological findings are therefore conceptually consistent with a recent study showing greater decreases in self-reported emotional reactions during reappraisal implementation in individuals scoring higher on trait reappraisal (McRae et al., 2012). Trait worry, on the other hand, was associated with parietal LPP magnitude increases during positive reap- 
A

High Trait Reappraisal
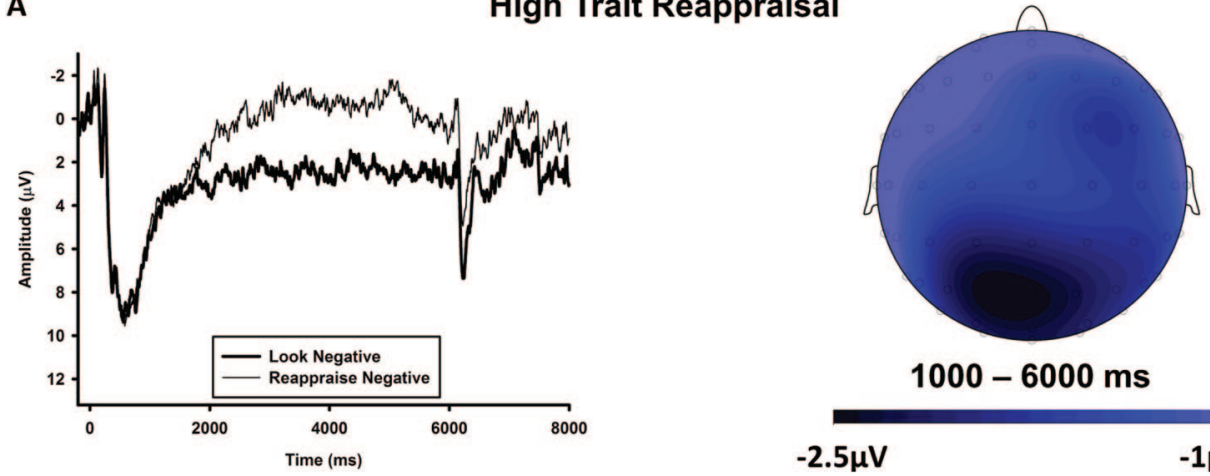

B

Low Trait Reappraisal
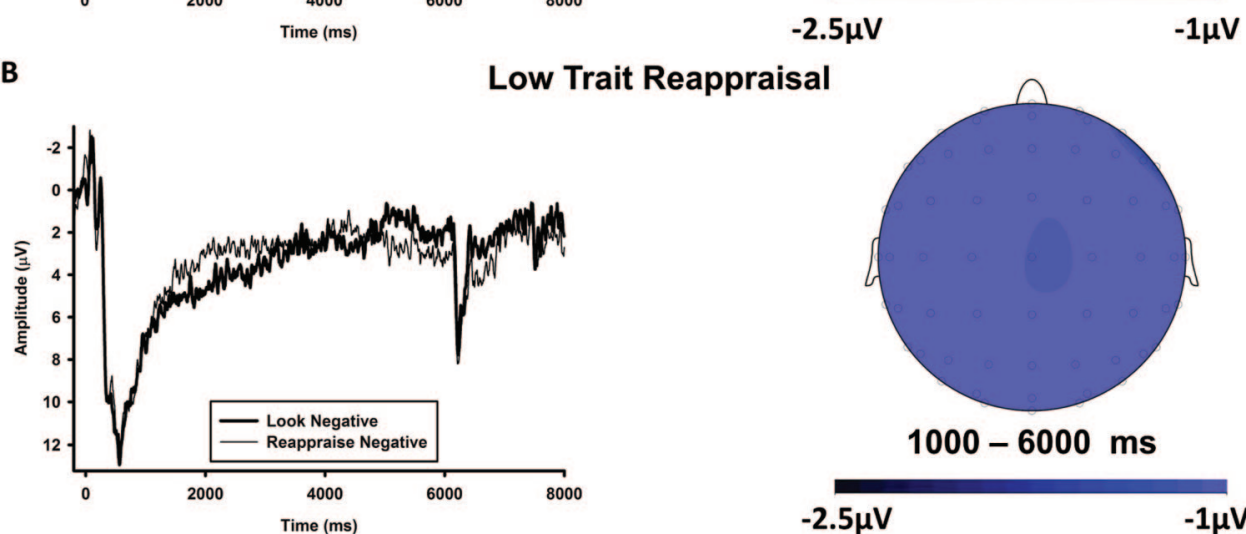

Figure 3. Picture-locked ERPs, pooled at parietal sites (CPz, P1, Pz, P2, POz), shown separately for high (A) and low (B) trait reappraisers (defined by a median split procedure for graphical purposes only). Headmaps show the topographical distribution of the Reappraise Negative minus Look Negative difference wave for the two groups.

praisal implementation similar to those observed when individuals are instructed to increase negative emotions to unpleasant stimuli (Moser et al., 2009). This increase began earlier than the effect of trait reappraisal, around 400 milliseconds. However, it is important to note that worry was more uniquely related to early LPP increases whereas trait reappraisal seemed to account for worry's association with later LPP effects.

Further supporting the practice effects prediction was the observation that worry, but not trait reappraisal, was associated with enhanced SPN magnitude during the cue-to-picture period, suggesting that worriers engage in greater anticipatory and preparatory processes while waiting to reappraise the upcoming unpleasant scene (Aldao \& Mennin, 2012; Campbell-Sills et al., 2011; Goldin et al., 2009). Critically, rather than helping worriers regulate their emotions, this enhanced preparatory activity appeared to be ineffective in so far as worry predicted parietal LPP enhancements. Worriers also reported greater effort expenditure during positive reappraisal implementation, further underscoring their difficulty with this process.

\section{Additional Basic Science Considerations}

Some studies demonstrate that the largest SPN amplitudes are elicited in anticipation of the most arousing and motivationally relevant stimuli (for a review see Hajcak, Weinberg, MacNamara, \& Foti, 2012). These findings point to the possibility that the enhanced SPN amplitude we observed in worriers reflects in- creased anticipatory arousal elicited by the reappraisal cuesperhaps because of nervousness about effectively implementing positive reappraisal. This interpretation is further strengthened by the fact that worriers also showed enhanced LPPs during implementation of positive reappraisal, as the LPP is highly linked to arousal-related processes like subjective experiences of arousal (Hajcak et al., 2012). Together, our findings might therefore reflect the exaggerated arousal response worriers have when trying to implement an adaptive emotion regulation strategy. This interpretation need not be at odds with that proposed above, as arousal might serve to prime preparatory and anticipatory processes or arousal, preparation, and anticipation may all reflect manifestations of the same mechanism at play (Brunia et al., 2012).

There is also evidence suggesting that fixating on less arousing aspects of emotional pictures may account for reduced LPP (Dunning \& Hajcak, 2009; Hajcak, Dunning, \& Foti, 2009) and modulations of various brain regions (van Reekum et al., 2007) during reappraisal. Regarding the LPP, directing fixation to nonarousing aspects of unpleasant images seems to result in reduced amplitudes in earlier and later time windows-beginning around $600 \mathrm{~ms}-$ suggesting that such manipulations affect both attention allocation and memory stages (Hajcak et al., 2009). Moreover, a recent study showed that decreases in emotional experience and facial expressions of emotion during reappraisal were actually most pronounced when individuals fixed their gaze on the most arousing aspects of unpleasant pictures (Urry, 2010). Together, extant re- 
A

High Trait Worry

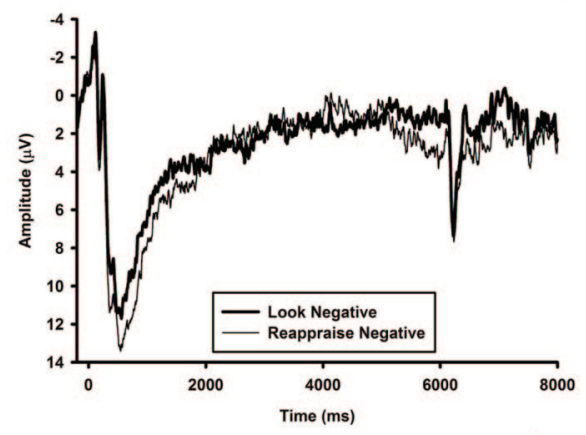

Low Trait Worry

B

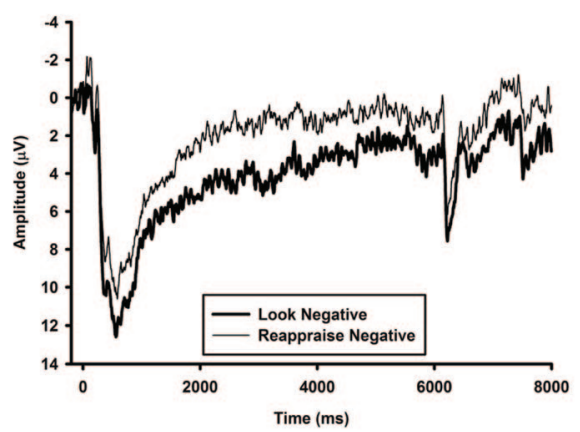

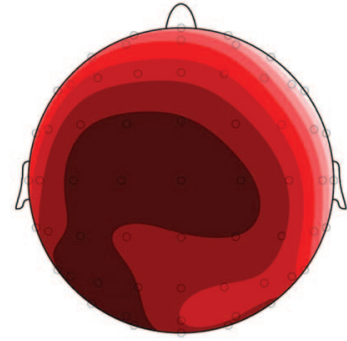

$400-1000 \mathrm{~ms}$
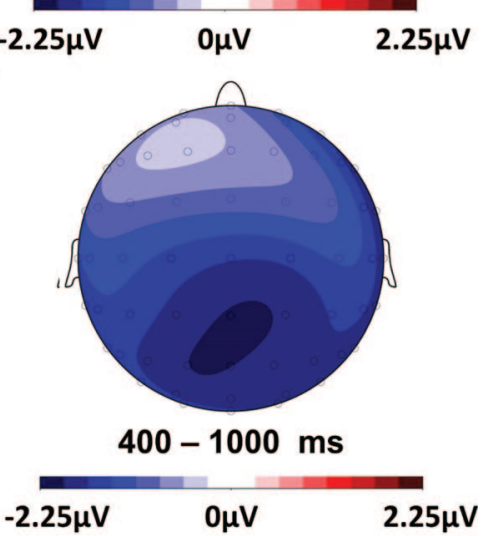

Figure 4. Picture-locked ERPs, pooled at parietal sites (CPz, P1, Pz, P2, POz), shown separately for high (A) and low (B) trait worriers (defined by a median split procedure for graphical purposes only). Headmaps show the topographical distribution of the Reappraise Negative minus Look Negative difference wave for both groups.

search provides support for our suggestion that reductions of later LPP time windows by positive reappraisal reflect changes in elaborative memory and meaning-making processes that follow initial attention allocation dedicated to evaluating the motivational significance of the stimuli.

\section{Clinical Implications}

These findings raise the interesting possibility that parietal LPP modulations may represent transdiagnostic biomarkers of cognitive change insomuch as trait reappraisal is linked to psychological well-being (Gross \& John, 2003) and worry is linked to a range of emotional disorders (Barlow, 2002; Brown \& Barlow, 2009). Three observations support this possibility. First, instructing people to positively reappraise their feelings reliably predicted LPP decreases in our study. Second, trait reappraisal and worry differentially modulated the parietal LPP in expected directions on trials where people were instructed to positively reappraise their emotions - trait reappraisal predicted greater parietal LPP decreases whereas worry predicted greater parietal LPP increases. The timing of these individual difference relationships is also important to highlight in that trait reappraisal appeared to influence later memory and meaning making processes whereas worry's effects were most strongly observed during earlier attention allocation stages of information processing. Thus, different neural processes-indexed by early versus late parietal LPP modulations - underlying positive reappraisal implementation might provide unique biomarkers of maladaptive versus adaptive cognitive change. Enhanced SPN may also represent a marker of maladaptive emotion regulation to the extent that it was present in worriers.

The current findings also show, for the first time, that worry, measured along a continuum, is associated with paradoxical increases in emotion processing during reappraisal. Indeed, our recruitment strategy yielded a substantial spread in worry scores such that a significant proportion of individuals reported suffering from severe worry. By demonstrating associations between LPP modulations during positive reappraisal and worry and trait reappraisal measured along continua our findings have etiologic significance in that LPP modulations during positive reappraisal implementation might serve as markers of risk for the development of emotional disorders, which can be difficult to achieve with older individuals already diagnosed with full-blown mental illness. Our findings further suggest that enhanced SPN amplitude during reappraisal cue processing might also serve as a marker of risk for worry-related psychopathology.

The current findings also have important potential treatment implications. Instigating cognitive change, either directly through cognitive restructuring or indirectly through exposure to evocative situations, is a critical treatment target that mediates CBT outcomes (Clark \& Beck, 2010; Foa \& Kozak, 1986; Goldin et al., 2013; Hofmann et al., 2007). To the extent that the parietal LPP modulations reported here provide an index of cognitive change, this waveform could be used to predict and chart progress in CBT using a noninvasive neural measure. Likewise, SPN amplitude could be used to predict facility with cognitive restructuring tech- 

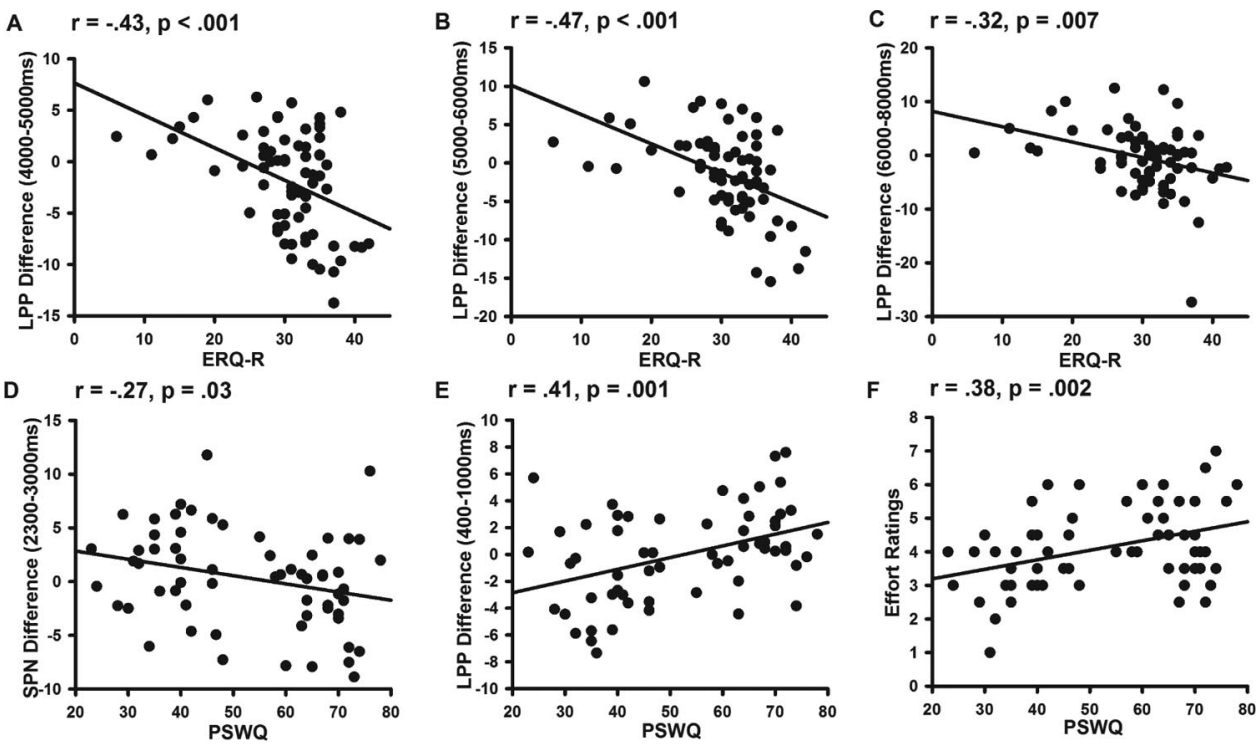

Figure 5. Scatterplots depicting relationships between the ERQ-R and LPP measures (A, B, C) and between the PSWQ and ERP and effort measures (D, E, F). ERP differences were calculated as Reappraise Negative minus Look Negative trials. Effort ratings were averaged across Reappraise Negative and Look Negative trials.

niques. Parietal LPP and frontal SPN modulation could also be used as neurofeedback in a reappraisal training paradigm in which individuals practice implementing positive reappraisal in the laboratory context to alleviate symptoms.

\section{Limitations and Future Directions}

First, it is important to note that we did not assess diagnostic criteria of any mental disorder in the current study. Thus, we cannot be sure that any of our participants suffered from "disorder" per se. Future investigations that focus on people suffering from diagnosed anxiety and related disorders will therefore be important to corroborate these findings. Future research should also consider other transdiagnostic constructs tapping negative thinking patterns that are regarded as maladaptive cognitive emotion regulation strategies, such as rumination (Aldao et al., 2010; Watkins, 2008).

Second, interpretations of the functional significance of ERPs should also be made with caution (cf. Luck, 2005). One should not assume a 1-to-1 correspondence between the ERP modulations observed here and the suggested psychological processes. Indeed, the psychological meaning of ERP effects is inferred from the amplitude and timing differences observed between experimental manipulations (e.g., between passive viewing and positive reappraisal instructions). As can be the case, different experimental manipulations may lead to similar ERP modulations-we acknowledged such an instance regarding different interpretations of SPN effects (preparation vs. arousal). Similarly, broad and longlasting ERPs like the LPP, in particular, likely result from several underlying neural mechanisms (Luck, 2005) giving rise to a number of psychological processes. Nonetheless, we have attempted to provide justification for our ERP interpretations using findings from a number of converging lines of research, and have acknowledged alternative interpretations of our findings. Future research should continue to adjudicate between possible explanations for such reappraisal-related ERP findings that appear to help distinguish individuals from one another on the basis of worry symptoms and trait reappraisal.

Third, there is a disconnect between how individual differences studies define reappraisal and how experimental studies operationalize it. That is, individual differences research using the ERQ (e.g., Gross \& John, 2003) does not distinguish between the frequency of use of positive versus detached reappraisal (or other types of reappraisal, for that matter) despite the fact that different types of reappraisal are typically separated in experimental studies, and linked with different outcomes (e.g., Kross \& Ayduk, 2011; Shiota \& Levenson, 2009; Ochsner et al., 2004). Future work aimed at developing more specific individual difference measures of various types of reappraisal is therefore warranted and needed. That experimental work can inform individual differences constructs and vice versa typifies the sort of bidirectional flow of information from basic to applied science that will propel this area forward. Furthermore, studies like the current one help to broaden the scope of our constructs to include referents in both behavior and biology.

Finally, future research is also needed to examine the developmental implications of the current findings. Two issues seem to us particularly important in this regard. First, recent work indicates that children suffering from anxiety disorders demonstrate difficulty generating reappraisals of negative stimuli, report using reappraisal less often on a daily basis than healthy controls, and perceive reappraisal as being less efficacious in reducing negative emotions than healthy controls (Carthy, Horesh, Apert, \& Gross, 2010; Carthy, Horesh, Apert, Edge, \& Gross, 2010). Given our ERP findings indicating that collegeaged worriers show similar difficulties implementing positive 
reappraisal, an interesting next step would be to examine whether worried children already evidence enhanced SPN and LPP amplitudes during positive reappraisal implementation. Such a finding would provide much needed neural evidence speaking to the role of emotion regulation deficits in early expressions of anxiety problems. Second, might the individual differences in ERP responses during positive reappraisal implementation observed here serve as early markers of healthy versus unhealthy emotional development? On average, younger people use reappraisal less often than older people and report higher levels of negative emotion (John \& Gross, 2004). Neuroimaging data suggest the possibility that such age differences reflect maturational changes in frontal cognitive control brain regions important for the implementation of reappraisal that continue to develop well into early adulthood (McRae et al., 2012). Using our ERP methodology and an individual differences perspective with larger samples may allow us to identify individual trajectories of healthy versus unhealthy emotional development that emerge early in life and have later predictive value.

\section{Conclusion}

The current findings provide novel insights into the neural underpinnings of positive reappraisal and their relationship to individual differences in clinically relevant dimensions of trait reappraisal and worry. They highlight how positive reappraisal unfolds over time and suggest that the LPP and SPN may provide objective neural biomarkers of cognitive emotion regulation that have value for assessment and treatment of emotional disorders.

\section{References}

Aldao, A., \& Mennin, D. (2012). Pardoxical cardiovascular effects of implementing adaptive emotion regulation strategies in generalized anxiety disorder. Behaviour Research and Therapy, 50, 122-130. doi: 10.1016/j.brat.2011.12.004

Aldao, A., Nolen-Hoeksema, S., \& Schweizer, S. (2010). Emotion regulation strategies and psychopathology: A meta analysis. Clinical Psychology Review, 30, 217-237. doi:10.1016/j.cpr.2009.11.004

American Psychiatric Association. (2013). Diagnostic and statistical manual of mental disorders (5th ed.). Washington, DC: American Psychiatric Association. doi:10.1176/appi.books.9780890425596.910646

Anderer, P., Semlitsch, H. V., \& Saletu, B. (1996). Multichannel auditory event-related brain potentials: Effects of normal aging on the scalp distribution of N1, P2, N2 and P300 latencies and amplitudes. Electroencephalography \& Clinical Neurophysiology, 99, 458-472. doi: 10.1016/S0013-4694(96)96518-9

Andrews, G., Hobbs, M. J., Borkovec, T. D., Beesdo, K., Craske, M. G., Heimberg, R. G., \& Stanley, M. A. (2010). Generalized worry disorder: A review of $D S M-I V$ generalized anxiety disorder and options for DSM-V. Depression and Anxiety, 27, 134-147. doi:10.1002/da.20658

Barlow, D. H. (2002). Anxiety and its disorders: The nature and treatment of anxiety and panic (2nd ed.). New York, NY: Guilford Press.

Beck, A. T., Emery, G., \& Greenberg, R. L. (1985). Anxiety disorders and phobias: A cognitive perspective. New York, NY: Basic Books.

Beck, A. T., Rush, A. J., Shaw, B. F., \& Emery, G. (1979). Cognitive therapy of depression. New York, NY: Guilford Press.

Beck, A. T., Steer, R. A., Ball, R., \& Ranieri, W. (1996). Comparison of Beck Depression Inventories-IA and -II in psychiatric outpatients. Jour- nal of Personality Assessment, 67, 588-597. doi:10.1207/ s15327752jpa6703_13

Behar, E., Alcaine, O., Zuellig, A. R., \& Borkovec, T. D. (2003). Screening for generalized anxiety disorder using the Penn State Worry Questionnaire: A receiver operating characteristic analysis. Journal of Behavior Therapy and Experimental Psychiatry, 34, 25-43. doi:10.1016/S00057916(03)00004-1

Bernat, E. M., Cadwallader, M., Seo, D., Vizueta, N., \& Patrick, C. J. (2011). Effects of instructed emotion regulation on valence, arousal, and attentional measures of affective processing. Developmental Neuropsychology, 36, 493-518. doi:10.1080/87565641.2010.549881

Borkovec, T. D. (1985). Worry: A potentially valuable concept. Behaviour Research and Therapy, 23, 481-483. doi:10.1016/00057967(85)90178-0

Borkovec, T. D. (1994). The nature, functions, and origins of worry. In G. Davey \& F. Tallis (Eds.), Worrying: Perspectives on theory, assessment, and treatment (pp. 5-33). New York, NY: Wiley.

Borkovec, T. D., Alcaine, O., \& Behar, E. S. (2004). Avoidance theory of worry and generalized anxiety disorder. In R. Heimberg, D. Mennin, \& C. Turk (Eds.), Generalized anxiety disorder: Advances in research and practice (pp. 77-108). New York, NY: Guilford Press.

Borkovec, T. D., Robinson, E., Pruzinsky, T., \& DePree, J. A. (1983). Preliminary exploration of worry: Some characteristics and processes. Behaviour Research and Therapy, 21, 9-16. doi:10.1016/00057967(83)90121-3

Brown, T. A., \& Barlow, D. H. (2009). A proposal for a dimensional classification system based on the shared features of the DSM-IV anxiety and mood disorders: Implications for assessment and treatment. Psychological Assessment, 21, 256-271. doi:10.1037/a0016608

Brunia, C. H. M., Boxtel, G. J. M. van, \& Böcker, K. B. E. (2012). Negative slow waves as indices of anticipation: The Bereitschaftspotential, the Contingent Negative Variation, and the Stimulus-Preceding Negativity. In S. J. Luck \& E. S. Kappenman (Eds.), The Oxford handbook of event-related potential components (pp. 189-207). New York, NY: Oxford University Press.

Cahill, L., Haier, R. J., White, N. S., Fallon, J., Kilpatrick, L., Lawrence, C., . . Alkire, M. T. (2001). Sex-related difference in amygdala activity during emotionally influenced memory storage. Neurobiology of Learning and Memory, 75, 1-9. doi:10.1006/nlme.2000.3999

Campbell-Sills, L., Barlow, D. H., Brown, T. A., \& Hofmann, S. G. (2006). Effects of suppression and acceptance on emotional responses on individuals with anxiety and mood disorders. Behaviour Research and Therapy, 44, 1251-1263. doi:10.1016/j.brat.2005.10.001

Campbell-Sills, L., Simmons, A. N., Lovero, K. L., Rochlin, A. A., Paulus, M. P., \& Stein, M. B. (2011). Functioning of neural systems supporting emotion regulation in anxiety-prone individuals. NeuroImage, 54, 689696. doi:10.1016/j.neuroimage.2010.07.041

Canli, T., Desmond, J. E., Zhao, Z., \& Gabrieli, J. D. E. (2002). Sex differences in the neural encoding of emotional experiences. Proceed ings of the National Academy of Sciences of the United States of America, 99, 10789-10794. doi:10.1073/pnas.162356599

Carthy, T., Horesh, N., Apert, A., Edge, M. D., \& Gross, J. J. (2010). Emotional reactivity and cognitive regulation in anxious children. $B e$ haviour Research and Therapy, 48, 384-393. doi:10.1016/j.brat.2009 .12 .013

Carthy, T., Horesh, N., Apert, A., \& Gross, J. J. (2010). Patterns of emotional reactivity and regulation in children with anxiety disorders. Journal of Psychopathology and Behavioral Assessment, 32, 23-36. doi:10.1007/s10862-009-9167-8

Clark, D. M. (2001). A cognitive perspective on social phobia. In W. R. Crozier \& L. E. Alden (Eds.), International handbook of social anxiety (pp. 405-430). Chichester, England: Wiley.

Clark, D. A., \& Beck, A. T. (2010). Cognitive theory and therapy of anxiety and depression: Convergence with neurobiological findings. 
Trends in Cognitive Sciences, 14, 418-424. doi:10.1016/j.tics.2010.06 .007

Clark, L. A., \& Watson, D. (1991). Tripartite model of anxiety and depression: Psychometric evidence and taxonomic implications. Journal of Abnormal Psychology, 100, 316-336. doi:10.1037/0021-843X.100.3 .316

Cuthbert, B. N., Schupp, H. T., Bradley, M. M., Birbaumer, N., \& Lang, P. J. (2000). Brain potentials in affective picture processing: Covariation with autonomic arousal and affective report. Biological Psychology, 52, 95-111. doi:10.1016/S0301-0511(99)00044-7

Dan-Glauser, E. S., \& Gross, J. J. (2011). The temporal dynamics of two response-focused forms of emotion regulation: Experiential, expressive, and autonomic consequences. Psychophysiology, 48, 1309-1322. doi: 10.1111/j.1469-8986.2011.01191.x

Denny, B., Silvers, J., \& Ochsner, K. N. (2009). How we heal what we don't want to feel: The functional neural architecture of emotion regulation. In A. M. Kring \& D. M. Sloan (Eds.), Emotion regulation and psychopathology: A transdiagnostic approach to etiology and treatment (pp. 59-87). New York, NY: Guilford Press.

Dunning, J. P., \& Hajcak, G. (2009). See no evil: Directing visual attention within unpleasant images modulates the electrocortical response. Psychophysiology, 46, 28-33. doi:10.1111/j.1469-8986.2008.00723.x

Ehring, T., Tuschen-Caffier, B., Schnülle, J., Fischer, S., \& Gross, J. J. (2010). Emotion regulation and vulnerability to depression: Spontaneous versus instructed use of emotion suppression and reappraisal. Emotion, 10, 563-572. doi:10.1037/a0019010

Foa, E. B., \& Kozak, M. J. (1986). Emotional processing of fear: Exposure to corrective information. Psychological Bulletin, 99, 20-35. doi: 10.1037/0033-2909.99.1.20

Foti, D., \& Hajcak, G. (2008). Deconstructing reappraisal: Descriptions preceding arousing pictures modulate the subsequent neural response. Journal of Cognitive Neuroscience, 20, 977-988. doi:10.1162/jocn.2008 .20066

Goldin, P. R., Jazaieri, H., Ziv, M., Kraemer, H., Heimberg, R. G., \& Gross, J. J. (2013). Changes in positive self-views mediate the effect of cognitive-behavioral therapy for social anxiety disorder. Clinical Psychological Science, 1, 301-310. doi:10.1177/2167702613476867

Goldin, P. R., Manber-Ball, T., Werner, K., Heimberg, R., \& Gross, J. J. (2009). Neural mechanisms of cognitive reappraisal of negative selfbeliefs in social anxiety disorder. Biological Psychiatry, 66, 1091-1099. doi:10.1016/j.biopsych.2009.07.014

Gratton, G., Coles, M. G. H., \& Donchin, E. (1983). A new method for off-line removal of ocular artifact. Electroencephalography \& Clinical Neurophysiology, 55, 468-484. doi:10.1016/0013-4694(83)90135-9

Gross, J. J. (1998). Antecedent- and response-focused emotion regulation: Divergent consequences for experience, expression, and physiology. Journal of Personality and Social Psychology, 74, 224-237. doi: 10.1037/0022-3514.74.1.224

Gross, J. J., \& John, O. P. (2003). Individual differences in two emotion regulation processes: Implications for affect, relationships, and wellbeing. Journal of Personality and Social Psychology, 85, 348-362. doi: $10.1037 / 0022-3514.85 .2 .348$

Gross, J. J., \& Thompson, R. A. (2007). Emotion regulation: Conceptual foundations. In J. J. Gross (Ed.), Handbook of emotion regulation (pp. 3-24). New York, NY: Guilford Press.

Hajcak, G., Dunning, J. P., \& Foti, D. (2009). Motivated and controlled attention to emotion: Time-course of the late positive potential. Clinical Neurophysiology, 120, 505-510. doi:10.1016/j.clinph.2008.11.028

Hajcak, G., \& Nieuwenhuis, S. T. (2006). Reappraisal modulates the electrocortical response to negative pictures. Cognitive, Affective, and Behavioral Neuroscience, 6, 291-297. doi:10.3758/CABN.6.4.291

Hajcak, G., \& Olvet, D. M. (2008). The persistence of attention to emotion: Brain potentials during and after picture presentation. Emotion, 8, 250255. doi: $10.1037 / 1528-3542.8 .2 .250$
Hajcak, G., Weinberg, A., MacNamara, A., \& Foti, D. (2012). ERPs and the study of emotion. In S. J. Luck \& E. S. Kappenman (Eds.), The Oxford handbook of event-related potential components (pp. 441-474). New York, NY: Oxford University Press.

Harvey, A. G., Watkins, E., Mansell, W., \& Shafran, R. (2004). Cognitive behavioural processes across psychological disorders: A transdiagnostic approach to research and treatment. Oxford, UK: Oxford University Press.

Hofmann, S. G., Meuret, A. E., Rosenfield, D., Suvak, M. K., Barlow, D. H., Gorman, J. M. . . Woods, S. W. (2007). Preliminary evidence for cognitive mediation during cognitive-behavioral therapy of panic disorder. Journal of Consulting and Clinical Psychology, 75, 374-379. doi:10.1037/0022-006X.75.3.374

Holmes, A., Nielsen, M. K., Tipper, S., \& Green, S. (2009). An electrophysiological investigation into the automaticity of emotional face processing in high versus low trait anxious individuals. Cognitive, Affective \& Behavioral Neuroscience, 9, 323-334. doi:10.3758/CABN.9.3.323

Jaffee, S. R., Caspi, A., Moffitt, T. E., Dodge, K. A., Rutter, M., Taylor, A., $\&$ Tully, L. A. (2005). Nature $\times$ nurture: Genetic vulnerabilities interact with physical maltreatment to promote conduct problems. Development and Psychopathology, 17, 67-84. doi:10.1017/S0954579405050042

Jamieson, J. P., Nock, M. K., \& Mendez, W. B. (2012). Mind over matter: Reappraising arousal improves cardiovascular and cognitive responses to stress. Journal of Experimental Psychology: General, 141, 417-422. doi:10.1037/a0025719

John, O. P., \& Gross, J. J. (2004). Healthy and unhealthy emotion regulation: Personality processes, individual differences, and life span development. Journal of Personality, 72, 1301-1334.

Kessler, R. C., Berglund, P., Demler, O., Jin, R., Merikangas, K. R., \& Walters, E. E. (2005). Lifetime prevalence and age-of-onset distributions of $D S M-I V$ disorders in the national comorbidity survey replication. Archives of General Psychiatry, 62, 593-602. doi:10.1001/archpsyc.62 .6 .593

Kessler, R. C., Petukhova, M., Sampson, N. A., Zaslavsky, A. M., \& Wittchen, H. U. (2012). Twelve-month and lifetime prevalence and lifetime morbid risk of anxiety and mood disorders in the United States. The International Journal of Methods in Psychiatric Research, 21, 169-184. doi:10.1002/mpr.1359

Koenig, S., \& Mecklinger, A. (2008). Electrophysiological correlates of encoding and retrieving emotional events. Emotion, 8, 162-173. doi: 10.1037/1528-3542.8.2.162

Krompinger, J. W., Moser, J. S., \& Simons, R. F. (2008). Modulations of the electrophysiological response to pleasant stimuli by cognitive reappraisal. Emotion, 8, 132-137. doi:10.1037/1528-3542.8.1.132

Kross, E., \& Ayduk, O. (2009). Boundary conditions and buffering effects. Does depressive symptomology moderate the effectiveness of selfdistancing for facilitating adaptive emotional analysis. Journal of Research in Personality, 43, 923-927. doi:10.1016/j.jrp.2009.04.004

Kross, E., \& Ayduk, O. (2011). Making meaning out of negative experiences by self-distancing. Current Directions in Psychological Science, 20, 187-191. doi:10.1177/0963721411408883

Kross, E., Gard, D., Deldin, P., Clifton, J., \& Ayduk, O. (2012). Asking why from a distance: Its cognitive and emotional consequences for people with Major Depressive Disorder. Journal of Abnormal Psychology, 121, 559-569. doi:10.1037/a0028808

Krueger, R. F. (1999). The structure of common mental disorders. Archives of General Psychiatry, 56, 921-926. doi:10.1001/archpsyc.56.10.921

Lang, P. J., Bradley, M. M., \& Cuthbert, B. N. (1999). International Affective Picture System: Instruction manual and affective ratings. Tech. Rep. No. A-4. Gainesville, FL: The Center for Research in Psychophysiology, University of Florida.

Lewinsohn, P. M., Gotlib, I. H., Lewinsohn, M., Seeley, J. R., \& Allen, N. B. (1998). Gender differences in anxiety disorders and anxiety 
symptoms in adolescents. Journal of Abnormal Psychology, 107, 109117. doi:10.1037/0021-843X.107.1.109

Liu, Y., Huang, H., McGinnis-Deweese, M., Keil, A., \& Ding, M. (2012). Neural substrate of the late positive potential in emotional processing. The Journal of Neuroscience, 32, 14563-14572. doi:10.1523/ JNEUROSCI.3109-12.2012

Luck, S. J. (2005). An introduction to the event-related potential technique. Cambridge, MA. The MIT Press.

MacNamara, A., Foti, D., \& Hajcak, G. (2009). Tell me about it: Neural activity elicited by emotional stimuli and preceding descriptions. Emotion, 9, 531-543. doi:10.1037/a0016251

McEvoy, L. K., Pellouchoud, E., Smith, M. E., \& Gevins, A. (2001). Neurophysiological signals of working memory in normal. Cognitive Brain Research, 11, 363-376.

McRae, K., Hughes, B., Chopra, S., Gabrieli, J. D. E., Gross, J. J., \& Ochsner, K. N. (2010). The neural bases of distraction and reappraisal. Journal of Cognitive Neuroscience, 22, 248-262. doi:10.1162/jocn.2009 .21243

McRae, K., Jacobs, S. E., Ray, R. D., John, O. P., \& Gross, J. J. (2012). Individual differences in reappraisal ability: Links to reappraisal frequency, well-being, and cognitive control. Journal of Research in Personality, 7, 253-262. doi:10.1093/scan/nsq103

McRae, K., Ochsner, K. N., Mauss, I. B., Gabrieli, J. J. D., \& Gross, J. J. (2008). Gender difference in emotion regulation: An fMRI study of cognitive reappraisal. Group Processes \& Intergroup Relations, 11, 143-162. doi:10.1177/1368430207088035

Mennin, D. S., Heimberg, R. G., Turk, C. L., \& Fresco, D. M. (2005). Preliminary evidence for an emotion dysregulation model of generalized anxiety disorder. Behaviour Research and Therapy, 43, 1281-1310. doi:10.1016/j.brat.2004.08.008

Meyer, T. J., Miller, M. L., Metzger, R. L., \& Borkovec, T. D. (1990). Development and validation of the Penn State Worry Questionnaire. Behaviour Research and Therapy, 28, 487-495. doi:10.1016/00057967(90)90135-6

Moran, T. P., Jendrusina, A. A., \& Moser, J. S. (2013). The psychometric properties of the late positive potential during emotion processing and regulation. Brain Research, 1516, 66-75. doi:10.1016/j.brainres.2013 .04 .018

Morris, S. E., \& Cuthbert, B. N. (2012). Research domain criteria: Cognitive systems, neural circuits, and dimensions of behavior. Dialogues in Clinical Neuroscience, 14, 29-37. Retrieved from http://www dialogues-cns.com/

Moser, J. S., Hajcak, G., Bukay, E., \& Simons, R. F. (2006). Intentional modulation of emotional responding to unpleasant pictures: An ERP study. Psychophysiology, 43, 292-296. doi:10.1111/j.1469-8986.2006 $.00402 . \mathrm{x}$

Moser, J. S., Krompinger, J. W., Dietz, J., \& Simons, R. F. (2009). Electrophysiological correlates of decreasing and increasing emotional responses to unpleasant pictures. Psychophysiology, 46, 17-27. doi: 10.1111/j.1469-8986.2008.00721.x

Moser, J. S., Most, S. B., \& Simons, R. F. (2010). Increasing negative emotions by reappraisal enhances subsequent cognitive control: A combined behavioral and electrophysiological study. Cognitive, Affective, and Behavioral Neuroscience, 10, 195-207. doi:10.3758/CABN.10.2 .195

Nes, L. S., \& Segerstrom, S. C. (2006). Dispositional optimism and coping: A meta-analytic review. Personality and Social Psychology Review, 10, 3235-3251. doi:10.1207/s15327957pspr1003_3

Newman, M. G., \& Llera, S. J. (2011). A new theory of experiential avoidance in generalized anxiety disorder: A review and synthesis of research supporting an avoidance of a negative emotional contrast. Clinical Psychology Review, 31, 371-382. doi:10.1016/j.cpr.2011.01 .008
Nitschke, J. B., Heller, W., Imig, J. C., McDonald, R. P., \& Miller, G. A (2001). Distinguishing dimensions of anxiety and depression. Cognitive Therapy and Research, 25, 1-22. doi:10.1023/A:1026485530405

Ochsner, K. N., \& Gross, J. J. (2005). The cognitive control of emotion. Trends in Cognitive Sciences, 9, 242-249. doi:10.1016/j.tics.2005.03 .010

Ochsner, K. N., Ray, R. D., Cooper, J. C., Robertson, E. R., Chopra, S., Gabrieli, J. D. E., \& Gross, J. J. (2004). For better or for worse: Neural systems supporting the cognitive down- and up-regulation of negative emotion. NeuroImage, 23, 483-499. doi:10.1016/j.neuroimage.2004.06 .030

Olofsson, J. K., Nordin, S., Sequeira, H., \& Polich, J. (2008). Affective picture processing: An integrative review of ERP findings. Biological Psychology, 77, 247-265. doi:10.1016/j.biopsycho.2007.11.006

Paul, S., Simon, D., Kniesche, R., Kathmann, N., \& Endrass, T. (2013). Timing effects of antecedent-focused emotion regulation strategies. Biological Psychology, 94, 136-142.

Resick, P. A., \& Schnicke, M. K. (1992). Cognitive processing therapy for sexual assault victims. Journal of Consulting and Clinical Psychology, 60, 748-756. doi:10.1037/0022-006X.60.5.748

Ruscio, A. M., Borkovec, T. D., \& Ruscio, J. (2001). A taxometric investigation of the latent structure of worry. Journal of Abnormal Psychology, 111, 412-422. doi:10.1037//0021-843X.130.3.413

Sabatinelli, D., Bradley, M. M., Fitzsimmons, J. R., \& Lang, P. J. (2005) Parallel amygdala and inferotemporal activation reflect emotional intensity and fear relevance. Neurolmage, 24, 1265-1270. doi:10.1016/j neuroimage.2004.12.015

Sabatinelli, D., Lang, P. J., Keil, A., \& Bradley, M. M. (2007). Emotional Perception: Correlation of functional MRI and event-related potentials Cerebral Cortex, 17, 1085-1091. doi:10.1093/cercor/bhl017

Sanislow, C. A., Pine, D. S., Quinn, K. J., Kozak, M. J., Garvey, M. A., Heinssen, R. K., Wang, P. S.-E., \& Cuthbert, B. N. (2010). Developing constructs for psychopathology research: Research domain criteria Journal of Abnormal Psychology, 119, 631-639. doi:10.1037/a0020909

Scharmüller, W., Leutgeb, V., Schäfer, A., Köchel, A., \& Schienle, A. (2011). Source localization of late electrocortical positivity during symptom provocation in spider phobia: An sLORETA study. Brain Research, 1397, 10-18. doi:10.1016/j.brainres.2011.04.018

Scheier, M. F., Weintraub, J. K., \& Carver, C. S. (1986). Coping with stress: Divergent strategies of optimists and pessimists. Journal of Personality and Social Psychology, 51, 1257-1264. doi:10.1037/0022-3514 .51.6.1257

Schienle, A., Köchel, A., \& Leutgeb, V. (2011). Frontal late positivity in dental phobia: A study on gender differences. Biological Psychology, 88 263-269. doi:10.1016/j.biopsycho.2011.08.010

Sheppes, G., \& Gross, J. J. (2011). Is timing everything? Temporal considerations in emotion regulation. Personality and Social Psychology Review, 15, 319-331. doi:10.1177/1088868310395778

Shiota, M. N., \& Levenson, R. W. (2009). Effects of aging on experimentally instructed detached reappraisal, positive reappraisal, and emotional behavior suppression. Psychology and Aging, 24, 890-900. doi:10.1037/ a0017896

Spielberger, C. D., \& Gorsuch, R. L. (1983). Manual for the State-Trait Anxiety Inventory (Form Y): Self-evaluation questionnaire. Palo Alto, CA: Consulting Psychologists Press.

Thiruchselvam, R., Blechert, J., Sheppes, G., Rydstrom, A., \& Gross, J. J. (2011). The temporal dynamics of emotion regulation: An EEG study of distraction and reappraisal. Biological Psychology, 87, 84-92. doi: 10.1016/j.biopsycho.2011.02.009

Urry, H. L. (2010). Seeing, thinking, and feeling: Emotion-regulating effects of gaze-directed cognitive reappraisal. Emotion, 10, 125-135. doi: $10.1037 / \mathrm{a} 0017434$ 
Van Boxtel, G. J. M., \& Böcker, K. B. E. (2004). Cortical measures of anticipation. Journal of Psychophysiology, 18, 61-76. doi:10.1027/ 0269-8803.18.23.61

van Reekum, C. M., Johnstone, T., Urry, H. L., Thurow, M. E., Schaefer, H. S., Alexander, A. L., \& Davidson, R. J. (2007). Gaze fixations predict brain activation during the voluntary regulation of picture-induced negative affect. NeuroImage, 36, 1041-1055. doi:10.1016/j.neuroimage 2007.03.052

Watkins, E. R. (2008). Constructive and unconstructive repetitive thought. Psychological Bulletin, 134, 163-206. doi:10.1037/0033-2909.134.2 .163

Watson, D. (2005). Rethinking the mood and anxiety disorders: A quantitative hierarchical model for DSM-V. Journal of Abnormal Psychology, 114, 522-536. doi:10.1037/0021-843X.114.4.522
York, D., Borkovec, T. D., Vasey, M., \& Stern, R. (1987). Effects of worry and somatic anxiety induction on thoughts, emotion and physiological activity. Behaviour Research and Therapy, 25, 523-526. doi:10.1016/ 0005-7967(87)90060-X

Zlomke, K. R., \& Hahn, K. S. (2010). Cognitive emotion regulation strategies: Gender differences and associations to worry. Personality and Individual Differences, 48, 408-413. doi:10.1016/j.paid.2009.11.007

Received April 24, 2013

Revision received October 28, 2013 Accepted December 30, 2013 